\title{
BMJ Open Association between participation in the Families First Home Visiting programme and First Nations families' public health outcomes in Manitoba, Canada: a retrospective cohort study using linked administrative data
}

Jennifer E Enns, ${ }^{\oplus 1}$ Mariette Chartier, ${ }^{1}$ Nathan Nickel, ${ }^{1}$ Dan Chateau, ${ }^{1}$ Rhonda Campbell, ${ }^{2}$ Wanda Phillips-Beck, ${ }^{2}$ Joykrishna Sarkar, ${ }^{1}$ Elaine Burland, ${ }^{1}$ Janelle Boram Lee, ${ }^{1}$ Alan Katz, ${ }^{1,3}$ Rob Santos, ${ }^{4}$ Marni Brownell ${ }^{1}$

To cite: Enns JE, Chartier M, Nickel N, et al. Association between participation in the Families First Home Visiting programme and First Nations families' public health outcomes in Manitoba, Canada: a retrospective cohort study using linked administrative data. BMJ Open 2019;9:e030386. doi:10.1136/ bmjopen-2019-030386

- Prepublication history and additional material for this paper are available online. To view please visit the journal online (http://dx.doi.org/10.1136/ bmjopen-2019-030386).

Received 12 March 2019 Revised 10 June 2019 Accepted 13 June 2019
D) Check for updates

(c) Author(s) (or their employer(s)) 2019. Re-use permitted under CC BY-NC. No commercial re-use. See rights and permissions. Published by BMJ.

For numbered affiliations see end of article.

\section{Correspondence to} Dr Jennifer E Enns; jennifer_enns@cpe.umanitoba. ca

\section{ABSTRACT}

Objective To determine whether the Families First Home Visiting (FFHV) programme, which provides home visiting services to families across Manitoba, is associated with improved public health outcomes among First Nations families facing multiple parenting challenges.

Design Retrospective cohort study using populationbased administrative data.

Setting Manitoba, Canada.

Participants First Nations children born in Manitoba in 2003-2009 $(n=4010)$ and their parents enrolled in FFHV compared with non-enrolled families with a similar risk profile.

Intervention FFHV supports public health in Manitoba by providing home visiting services to First Nations and non-First Nations families with preschool children and connecting them with resources in their communities.

Outcomes Predicted probability (PP) and relative risk (RR) of childhood vaccination, parental involvement in community support programmes and children's development at school entry.

Results FFHV participation was associated with higher rates of complete childhood vaccination at age 1 (PP: FFHV 0.715, no FFHV 0.661, RR 1.08, 95\% Cl 1.03 to 1.14) and age 2 (PP: FFHV 0.465, no FFHV 0.401, RR $1.16,95 \% \mathrm{Cl} 1.08$ to 1.25 ), and with parental involvement in community support groups (PP: FFHV 0.149, no FFHV 0.097, RR 1.54, 95\% Cl 1.27 to 1.86 ). However, there was no difference between FFHV participants and non-participants in rates of children being vulnerable in at least one developmental domain at age 5 (PP: FFHV 0.551, no FFHV 0.557, RR 1.00, $95 \% \mathrm{Cl} 0.91$ to 1.11).

Conclusions FFHV supports First Nations families in Manitoba by promoting childhood vaccination and connecting families to parenting resources in their communities, thus playing an important role in fulfilling the mandate of public health practice.

\section{Strengths and limitations of this study}

- We used population-based data to identify First Nations participants in a Manitoba-wide home visiting programme and First Nations families who were eligible for this home visiting programme but not enrolled.

- Our use of inverse probability of treatment weights allowed us to estimate the potential programme effect on families who did not participate in the programme.

- The data were linkable at the individual level across health and social sectors, providing a wide range of variables for adjusting for differences between these groups.

- Despite precautions to ensure the study groups were similar, we cannot assume that we have adjusted for all possible confounders.

- The Families First Home Visiting programme is only available to First Nations and non-First Nations families living off-reserve in Manitoba; another home visiting programme (Strengthening Families) operating within First Nations communities (on-reserve) will be evaluated in a separate study.

\section{INTRODUCTION}

The overall goal of public health practice is to prevent disease and promote health, and thereby make the general population both healthier and safer. ${ }^{1}$ This is achieved through activities such as investigating health hazards, educating the public about various health-related issues, and linking individuals to health services and other resources. But public health practitioners also recognise the critical need for research and evaluation to identify effective intervention strategies for public health-related 
risks, as this evidence forms the basis of sound public health policies and decision making. ${ }^{2}$

Home visiting has been well established as an important public health strategy for supporting vulnerable families' health and social well-being. Home visiting aims to strengthen relationships between parents and their young children, enhance child health and development, and connect families to health services. Home visits by nurses and trained paraprofessionals typically begin in the prenatal period and continue through the first few years of a child's life. Studies from the past two decades show that home visiting improves pregnancy and birth outcomes, ${ }^{3-5}$ reduces instances of child injury or maltreatment, ${ }^{346}$ and supports children's development at school entry. ${ }^{35}$ Our recent work evaluating the Families First Home Visiting (FFHV) programme, which provides home visiting services to Indigenous and non-Indigenous families in Manitoba, Canada ('Indigenous' being the collective term for the original peoples of North America and their descendants; three broad groups are recognised in Canada: First Nations, Métis and Inuit), has shown that participation in the programme is associated with increased rates of childhood vaccination ${ }^{7}$ and fewer instances of child injury or maltreatment, ${ }^{8}$ and with lower rates of children being taken into care of child protective services. ${ }^{8}$ As well, FFHV is associated with reduced economic disparities in health and social outcomes between participating families and the general population. ${ }^{9}$

These evaluations of FFHV also provided anecdotal evidence that up to $40 \%$ of the families enrolled in the FFHV programme are Indigenous; however, literature describing engagement of Indigenous families in public health initiatives is scarce. The few studies available tend to suggest that Canadian Indigenous families are not always well connected to the public health system, ${ }^{10}{ }^{11}$ and there are many factors that likely contribute to this circumstance, including their experience of ongoing intergenerational trauma as a result of the residential school system, mistrust of public services and other social determinants of health. ${ }^{12-14}$ This is an important literature gap to address, because the unique historical and cultural factors that Indigenous families experience may alter the impact of home visiting programmes designed for and delivered to the general population. And while home visiting has been shown to be a promising intervention for improving public health at a population level, it is not known whether programmes like FFHV are effective specifically for Indigenous families. In this study, we partnered with First Nations researchers and programme leaders to examine whether FFHV is effective at improving public health outcomes for Manitoba First Nations families living in conditions of risk.

\section{METHODS}

\section{Study setting}

The FFHV programme operates in the central Canadian province of Manitoba. The population of Manitoba is generally representative of Canada as a whole across numerous health and social indicators, ${ }^{15}$ but has the highest proportion of First Nations residents among the 10 Canadian provinces. ${ }^{16}$ The FFHV programme is available to eligible Manitoba families living off-reserve (a parallel home visiting programme called Strengthening Families operates on-reserve in Manitoba and will be evaluated in a separate study). Briefly, eligibility for FFHV is determined by a two-stage process where public health nurses screen all Manitoba births during a home visit early in the postpartum period. Families with three or more risk factors on the newborn screen are further assessed using the Parent Survey. ${ }^{18}$ Families with a Parent Survey score of 25 or higher are eligible for FFHV, and may choose to enrol in the programme. On enrolment, trained paraprofessional home visitors begin to develop trusting relationships with the families under public health nurse supervision. Home visitors use the Growing Great Kids Curriculum ${ }^{19}$ to help improve parent-child relationships and healthy child development, and connect families with services. ${ }^{17}$ The FFHV programme has been fully described elsewhere. ${ }^{717}$

\section{Data sources}

The study used FFHV programme data linked with administrative data from the Population Research Data Repository at the Manitoba Centre for Health Policy, which contains population-based, individual-level data on over $99 \%$ of all children born in 1984-2014 in Manitoba. ${ }^{20}$ All records in the repository are deidentified, but can be linked together by use of a scrambled numeric identifier, and their validity for health and social research has been well documented..$^{21}{ }^{22}$ We used FFHV data to identify families who were screened for FFHV eligibility, and four data sets (FFHV data, the Indigenous and Northern Affairs Canada registry, data from a prenatal benefit programme in Manitoba, and income assistance data) to determine First Nations identity. Additional data sets drawn on for this study are listed in online supplementary table S1.

\section{Study cohort development}

The study cohort comprised all Manitoba First Nations families with children born in 2003-2009 who met the eligibility criteria for FFHV. Eligibility for FFHV is determined by a two-stage process, as shown in figure 1 . Public health nurses conduct a universal newborn screen in the postpartum period to collect information on biological, social and demographic factors such as First Nations identity, birth weight, mother's age, education, marital status, mental health and social isolation. Families with three or more risk factors that challenge their parenting and increase the risk of poor child outcomes are then further assessed using the Parent Survey, a 10-item questionnaire based on the Kempe Family Stress Checklist. ${ }^{18}$ Families with a score of 25 or more are eligible for FFHV.

In our study, we identified 5824 First Nations families who scored 'at risk' on the universal newborn screen (figure 1). Among these, 789 families had a Parent 


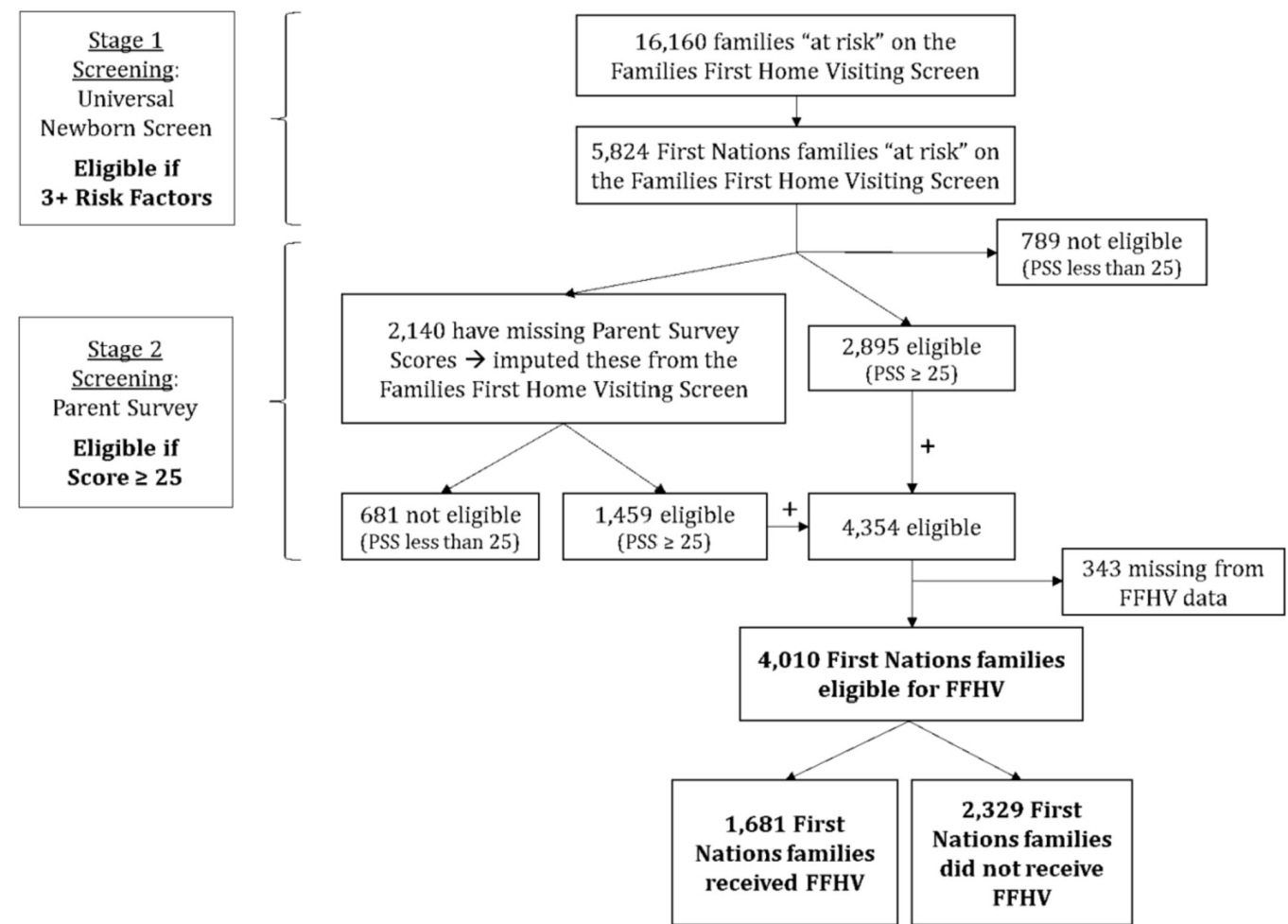

Figure 1 Study cohort development The flow chart identifies the number of First Nations families with births in 2003-2009 who were eligible for the Families First Home Visiting (FFHV) programme in Manitoba, Canada. PSS, Parent Survey Score.

Survey score less than 25 , and so were not eligible for FFHV. Among the remaining 5035 families, 2895 families had Parent Survey scores greater than or equal to 25, and so were eligible for the programme. Parent Survey scores for the final 2140 families were missing from the database. We used multiple imputations to estimate the missing Parent Survey scores. Briefly, using data from the universal newborn screen (see table 1), we applied Markov Chain Monte Carlo methods to fill in missing values 10 times, generating 10 complete data sets with the SAS V.9.4 MIANALYZE procedure. The results from the 10 complete data sets were then combined using MIANALYZE to reflect the fact that uncertainty still remains regarding the unknown values and to provide inferential results that are statistically valid according to the methods of Rubin. ${ }^{23}$ Using these methods, we determined that 1459 families among those with missing scores were eligible for FFHV (figure 1). The final study cohort included 4010 families with newborns, among whom 1681 families received the programme (exposed group) and 2329 families who met the eligibility criteria for FFHV but did not enrol in the programme (comparison group).

\section{Main outcomes}

We examined the following public health outcomes:

- Complete childhood vaccination at ages 1 and 2. Vaccination programmes are an important public health initiative that protect populations from the spread of debilitating infectious disease. All Manitoba residents, including First Nations people, have universal healthcare insurance, and coverage includes a programme of provincially funded vaccinations. Complete childhood vaccination was defined as receipt of all recommended vaccinations at ages 1 and 2 (online supplementary table S2).

- Parental participation in the Healthy Baby Community Support Program. Community programmes like the Healthy Baby Community Support Program provide social, educational and material resources for expectant women and parents with young children and help connect them to health and social services in their communities. Participation in the Healthy Baby Community Support Program was defined as at least one visit in the first year of an infant's life.

- Child development at age 5. There is a significant association between child development measures in kindergarten and key adult public health outcomes such as education, employment, justice system involvement and mental health. ${ }^{24}$ We used data from the Early Development Instrument (EDI), a 103-item questionnaire administered by kindergarten teachers to determine whether children scored as developmentally 'vulnerable' or 'not vulnerable' across five domains: physical health and well-being, emotional maturity, social competence, language and cognitive development, and communication skills and general knowledge.

\section{Propensity score weighting}

The degree to which families enrolled in FFHV differ from families in the comparison group on measured and unmeasured characteristics may bias estimates of 


\begin{tabular}{|c|c|}
\hline Variable & Description \\
\hline No prenatal care before 6 months & Mother did not attend prenatal care appointments before 6 months' gestation. \\
\hline Alcohol and/or drug use during pregnancy & Any alcohol and/or drug use by the mother during pregnancy. \\
\hline Smoking during pregnancy & Mother smoked during pregnancy. \\
\hline Social assistance & Family on social assistance/income support or having significant financial difficulties. \\
\hline Low education (mother) & Mother's highest level of education completed less than grade 12. \\
\hline Single-parent family & Parent or guardian not currently in common-law relationship or married. \\
\hline Antisocial (mother) & Mother exhibits antisocial behaviour. \\
\hline Schizophrenia (mother) & Mother diagnosed with schizophrenia or bipolar affective disorder. \\
\hline Mentally disabled (mother) & Mother has mental disability. \\
\hline Family history of disability & $\begin{array}{l}\text { Family history of a disability not detectable at birth that could affect development (eg, } \\
\text { deafness, mentally disabled/challenged). }\end{array}$ \\
\hline History of child abuse (mother) & Mother has a history of child abuse or neglect. \\
\hline Mother's age at first birth & Calculated using mother's date of birth and date of first birth. \\
\hline FFHV Parent Survey scores & Cumulative score of items on the Parent Survey. \\
\hline Socioeconomic factor index II & $\begin{array}{l}\text { An index based on Canadian census data that reflects non-medical social determinants } \\
\text { of health. }{ }^{40}\end{array}$ \\
\hline
\end{tabular}

*Included in the model for the outcome 'parental participation in the Healthy Baby Community Support Program' only. Variables are derived from the universal newborn screen, the FFHV data and the Manitoba Population Research Data Repository.

FFHV, Families First Home Visiting.

the association between FFHV and the outcomes. In an attempt to mitigate this bias, we identified potential confounding variables based on potential to influence exposure (FFHV enrolment) and outcomes (vaccination, parental participation in a community support programme, and early child development) (table 1). We adjusted for these variables using inverse probability of treatment weights (IPTWs) to create comparable groups, ${ }^{25}$ as follows: using logistic regression, we calculated propensity scores for each family in the study cohort to determine the probability that they would enrol in FFHV. The propensity scores were based on family characteristics likely to influence FFHV participation, such as alcohol use, mental illness and family relationship distress. Three sets of IPTWs were created, each corresponding to a different treatment effect: the average treatment effect (ATE), the average treatment effect on the treated (ATT) and the average treatment effect on the untreated (ATU). The ATE is the average programme effect on outcomes across the entire eligible population. The ATT is the average effect experienced by families who actually received FFHV, and the ATU is the potential average programme effect that would have been experienced among those who were eligible for FFHV but did not receive it. ${ }^{25}$

\section{Statistical analyses}

All analyses were performed using SAS V.9.4. ${ }^{26}$ We ran separate multiplicative models to estimate adjusted risk ratios for each outcome and obtain 95\% CIs (adjusted risk differences are shown in online supplementary table S3). ${ }^{27}$ Using an a priori significance level of $\mathrm{p}<0.05$, we applied generalised linear modelling to test for associations between FFHV programme enrolment and the outcomes, generating estimates of the ATE, ATT and ATU.

\section{Sensitivity testing}

While it is not possible to test directly whether the IPTWs controlled for all unmeasured confounding, $\gamma$ sensitivity analyses provide an assessment of how sensitive the results were to unmeasured confounders. We therefore calculated $\gamma$ sensitivity values for each statistically significant result to determine the strength of unmeasured confounding required to invalidate these results. ${ }^{25}$ 
Table 2 Characteristics of families eligible for FFHV, before and after applying IPTWs

\begin{tabular}{lccccc}
\hline & \multicolumn{2}{c}{ Before weighting } & & \multicolumn{2}{c}{ After weighting (ATE) } \\
\cline { 2 - 3 } \cline { 5 - 5 } & Received FFHV & $\begin{array}{l}\text { Did not } \\
\text { receive FFHV }\end{array}$ & Received FFHV & $\begin{array}{c}\text { Did not } \\
\text { receive FFHV }\end{array}$ \\
\hline No prenatal care before 6 months (\%) & 9.62 & 14.54 & 12.87 & 12.45 \\
\hline Prenatal screening for FFHV (\%) & 16.11 & 7.48 & 11.22 & 11.20 \\
\hline Alcohol and/or drug use during pregnancy (\%) & 44.79 & 45.76 & 44.63 & 45.05 \\
\hline Smoking during pregnancy (\%) & 58.85 & 63.36 & 61.76 & 61.22 \\
\hline Substance abuse (mother) (\%) & 5.30 & 3.73 & 4.44 & 4.17 \\
\hline Social isolation (\%) & 13.95 & 7.45 & 10.29 & 10.31 \\
\hline Social assistance (\%) & 82.55 & 85.77 & 84.52 & 84.43 \\
\hline Low education (mother) (\%) & 67.62 & 65.58 & 67.17 & 66.69 \\
\hline Single-parent family (\%) & 50.60 & 56.81 & 55.00 & 54.23 \\
\hline Antisocial (mother) (\%) & 2.68 & 2.63 & 2.59 & 2.67 \\
\hline Antisocial (father) (\%) & 6.45 & 5.25 & 6.17 & 5.93 \\
\hline Relationship distress (\%) & 25.39 & 17.88 & 21.51 & 21.52 \\
\hline Violence between parents (\%) & 12.09 & 10.28 & 11.16 & 10.96 \\
\hline Depression and/or anxiety (mother) (\%) & 31.22 & 26.48 & 28.92 & 28.36 \\
\hline Schizophrenia (mother) (\%) & 1.13 & 0.92 & 0.97 & 0.99 \\
\hline Mentally disabled (mother) (\%) & 2.08 & 0.86 & 1.32 & 1.25 \\
\hline Family history of disability (\%) & 4.39 & 3.71 & 3.97 & 3.89 \\
\hline History of child abuse (mother) (\%) & 31.11 & 21.36 & 25.30 & 25.22 \\
\hline FFHV Parent Survey score (mean) & 39.25 & 37.76 & 38.26 & 38.29 \\
\hline Mother's age at first birth (mean) & 19.35 & 19.07 & 19.25 & 19.22 \\
\hline Socioeconomic factor index II (mean) & 0.87 & 1.12 & 1.02 & 1.02 \\
\hline & & & &
\end{tabular}

ATE, average treatment effect; FFHV, Families First Home Visiting; IPTWs, inverse probability of treatment weights.

\section{Patient and public involvement}

As this was a secondary analysis of administrative data, no informed consent of patients/participants was required. However, this study was conducted in partnership with First Nations researchers and programme leaders, who serve as coinvestigators on the grant that funds this work and coauthors on this paper. Our First Nations partners codeveloped the study's research questions and guided decisions on which outcomes of interest would be pursued, actively participated in research team meetings to discuss the results of analyses and what these findings mean from a First Nations perspective, copresented the findings at national and regional conferences, and critically reviewed this and other publications stemming from the study. They also helped to arrange for members of the research team to visit several Manitoba First Nations communities to share study findings and hear the community members' perspectives on our work.

\section{RESULTS}

Before comparing public health outcomes between First Nations families who enrolled in FFHV and who were eligible but not enrolled, we made an effort to balance their characteristics by applying IPTWs (table 2). Before weighting, mothers in families who received FFHV were more likely to have been screened prenatally by a public health nurse, diagnosed with substance abuse, be socially isolated, experience relationship distress with parenting partner, diagnosed with depression and/or anxiety, and have a history of child abuse than mothers from families who did not receive FFHV. Recipients of FFHV were also less likely than non-recipients to be a single parent, to have smoked during their pregnancies or to be of low income. After weighting, the standardised differences between characteristics were reduced to less than $10 \%$, confirming that these characteristics were more evenly balanced and thus the study groups were more comparable.

The association between First Nations families being enrolled in FFHV and their children receiving a complete series of vaccinations is shown in table 3. Estimates of the ATE, the average programme effect on vaccination across the entire eligible population, show a significant association between families receiving FFHV and their children being vaccinated at ages 1 and 2: the probability of children in FFHV families completing a vaccination series was higher than for children from non-FFHV families; as well, the adjusted risk ratio for complete vaccination at ages 1 and 2 was significant. Moreover, when families' 
Table 3 Association between FFHV and vaccination completion for First Nations children

\begin{tabular}{|c|c|c|c|c|c|}
\hline & \multicolumn{2}{|c|}{ Predicted probability } & \multirow{2}{*}{$\begin{array}{l}\text { Adjusted risk } \\
\text { ratio }\end{array}$} & \multirow[b]{2}{*}{$95 \% \mathrm{Cl}$} & \multirow[b]{2}{*}{$\gamma$ Sensitivity } \\
\hline & FFHV & No FFHV & & & \\
\hline Complete vaccination at age 1 & $n=1190$ & $\mathrm{n}=1507$ & & & \\
\hline Unweighted & 0.720 & 0.655 & $1.100^{\star}$ & 1.049 to 1.153 & 50.4 \\
\hline Average treatment effect & 0.715 & 0.661 & $1.083^{*}$ & 1.032 to 1.135 & 40.5 \\
\hline Average effect on the treated & 0.719 & 0.669 & $1.074^{*}$ & 1.025 to 1.126 & 34.8 \\
\hline Average effect on the untreated & 0.712 & 0.654 & $1.089^{*}$ & 1.037 to 1.143 & 43.3 \\
\hline Complete vaccination at age 2 & $n=765$ & $n=905$ & & & \\
\hline Unweighted & 0.465 & 0.397 & $1.172^{*}$ & 1.087 to 1.262 & 52.9 \\
\hline Average treatment effect & 0.465 & 0.401 & $1.161^{*}$ & 1.078 to 1.249 & 50.6 \\
\hline Average effect on the treated & 0.465 & 0.406 & $1.146^{*}$ & 1.065 to 1.232 & 46.4 \\
\hline Average effect on the untreated & 0.465 & 0.397 & $1.172^{*}$ & 1.087 to 1.263 & 52.8 \\
\hline
\end{tabular}

The risk ratio is the predicted probability for FFHV families divided by the predicted probability for non-FFHV families. The $\gamma$ sensitivity value quantifies sensitivity to unmeasured confounding.

*Statistically significant at $\mathrm{p}<0.05$.

FFHV, Families First Home Visiting.

characteristics were weighted so that they were similar to those enrolled in FFHV (ATT) and to those not enrolled in FFHV (ATU), effect estimates of the risk ratio were still significant, the latter indicating that FFHV would potentially have been able to improve rates of vaccination completion for children in the comparison group if their families had been enrolled in the home visiting programme. The $\gamma$ values demonstrate that unmeasured confounders would have to be very strong in order to negate this effect.

Table 4 shows the association between enrolment in FFHV and parental involvement in the Healthy Baby Community Support Program. Estimates of the ATE demonstrate that FFHV families were more likely than non-FFHV families to attend the community support programme during the prenatal or postnatal period. The risk ratios between the two groups were also significant for estimates of the ATE, ATT and ATU, suggesting (as above) that families eligible for FFHV but not enrolled would potentially have been more likely to attend a community support programme if they had been receiving FFHV. These results were also deemed robust to unmeasured confounding as shown by the $\gamma$ sensitivity values.

We observed no association between FFHV enrolment and child development at age 5 , as measured by the EDI (online supplementary table S4). We examined the relationship between FFHV enrolment and children scoring as developmentally vulnerable in each of the five domains of the EDI. We also looked at the relationship between FFHV and a 'vulnerable' score in any one, two or three EDI domains (data not shown for two and three domains). These results indicate that FFHV, a programme delivered in the early years of a child's life, was not associated with improved developmental outcomes at school entry for First Nations children.

Table 4 Association between FFHV and First Nations parental participation in the Healthy Baby Community Support Program

\begin{tabular}{|c|c|c|c|c|c|}
\hline & \multicolumn{2}{|c|}{$\begin{array}{l}\text { Predicted } \\
\text { probability }\end{array}$} & \multirow{2}{*}{$\begin{array}{l}\text { Adjusted risk } \\
\text { ratio }\end{array}$} & \multirow[b]{2}{*}{$95 \% \mathrm{Cl}$} & \multirow[b]{2}{*}{$\gamma$ Sensitivity } \\
\hline & FFHV & No FFHV & & & \\
\hline Participation in the community support programme & $\mathrm{n}=315$ & $n=340$ & & & \\
\hline Unweighted & 0.161 & 0.091 & $1.766^{*}$ & 1.464 to 2.131 & 59.5 \\
\hline Average treatment effect & 0.149 & 0.097 & $1.536^{*}$ & 1.269 to 1.860 & 24.5 \\
\hline Average effect on the treated & 0.160 & 0.106 & $1.505^{\star}$ & 1.249 to 1.814 & 6.7 \\
\hline Average effect on the untreated & 0.142 & 0.091 & $1.561^{*}$ & 1.284 to 1.897 & 32.0 \\
\hline
\end{tabular}

The risk difference is the predicted probability for FFHV families minus the predicted probability for non-FFHV families; the risk ratio is the predicted probability for FFHV families divided by the predicted probability for non-FFHV families. The $\gamma$ sensitivity value quantifies sensitivity to unmeasured confounding.

*Statistically significant at $\mathrm{p}<0.05$.

FFHV, Families First Home Visiting. 


\section{DISCUSSION}

This study examines the role of home visiting in influencing public health outcomes among Manitoba First Nations families living off-reserve and enrolled in the provincially funded FFHV programme. Although FFHV is associated with improved health and social outcomes in the general population of Manitoba, evidence for First Nations families who enrolled in the programme has been lacking until now. In the current study, we found that enrolment in FFHV was associated with higher rates of childhood vaccination and greater participation in parenting support groups among First Nations families living in conditions of risk. Our results also indicated that families who were eligible for FFHV but did not enrol would potentially also see a significant benefit if they could be encouraged to participate in the programme.

Efforts made to ensure the cultural safety of public health initiatives for Indigenous people are important for programme uptake and efficacy. Several guiding frameworks for addressing inequities in Indigenous public health in a culturally safe way have emerged, most notably from Australia, ${ }^{28} 29$ while Canada has to some extent lagged behind in ensuring that provincial and national public health policies support Indigenous health and well-being. ${ }^{30}$ In Manitoba, the FFHV programme strives to employ Indigenous home visitors in areas where many Indigenous people live and encourage all staff to participate in cultural training. Staff are taught to recognise the historical and current realities of colonisation experienced by Indigenous peoples in Canada that add to their parenting challenges, including the racism they face and the multigenerational trauma that is the legacy of Canada's residential school system. ${ }^{13}$ Structural barriers such as economic disparities, substandard housing conditions, poor access to health services and inadequate staffing in remote communities also play a role in the marginalisation of Indigenous people. ${ }^{32-34}$ As a result of these and other challenges, First Nations individuals, families and communities experience high rates of mental disorders and family violence, ${ }^{35}$ factors that may make it difficult for them to engage in a public health intervention.

Home visiting programmes like FFHV can mitigate some of these adverse influences by building on the strengths of First Nations peoples and helping families facing multiple challenges gain confidence in their parenting skills, create a nurturing environment for their children and rebuild trust in the public health system. The positive outcomes we saw in this study, which include higher rates of childhood vaccinations (and thus greater contact with the public healthcare system) and stronger connections to community resources through the Healthy Baby Community Support Program, suggest that the family-centred and strength-based approaches on which FFHV is based are effective at improving these aspects of public health.
Whether FFHV is truly culturally safe for First Nations families has not yet been evaluated.

Despite the encouraging results for vaccination rates and community connections, we did not detect any association between FFHV enrolment and child development at age 5 , as measured by the EDI. This is perhaps not surprising, given that previous evaluations of FFHV similarly demonstrated little association between programme participation and child development indicators. For example, neither EDI scores nor levels of reading to children changed among FFHV families in the general population of Manitoba. ${ }^{17} 36$ It is possible that FFHV alone is not sufficient for improving child development scores, suggesting the need for programme enhancements or connections with other early childhood programmes.

A significant proportion (58\%) of eligible First Nations families in our study did not receive any services from FFHV. Other authors have also documented challenges in engaging and retaining families living in conditions of risk (sometimes termed 'hard-to-reach families') in programmes and improving child outcomes at a population level. ${ }^{37}{ }^{38}$ Some of the reasons families may not participate include family factors (mistrust of service providers, mental disorders, no telephone) and public health system challenges (high workloads, insufficient resources to accommodate all families, lack of experience with at-risk families). The very characteristics that prevent hard-to-reach families from participating in programmes like home visiting may influence how they respond to programme staff, the curriculum and the way the programme is implemented. ${ }^{39}$ For example, some families may not be open to developing a relationship with a home visitor. However, our findings indicate that the positive outcomes seen in participating families would be likely to occur even in hard-to-reach families. This suggests that greater investments in encouraging programme participation would be worthwhile and programme enhancements should be considered by administrators striving to achieve maximum programme impact.

\section{Strengths and limitations}

The strengths of this study include the use of population-based data generally representative of First Nations people across Canada, the wide range of factors available for adjusting for differences between study groups, and the ability to link individual-level FFHV programme data to multisectoral data sets to examine public health outcomes. The richness of the available data allowed us to construct a strong comparison group and conduct sensitivity analyses to ensure our results were not exceedingly susceptible to confounding factors. Using IPTWs enabled us to estimate the potential programme effect on children who did not receive the programme, which is particularly useful since we have included nearly all eligible families who did not receive the programme. This approach will assure policymakers that investments in engaging hard-to-reach families will improve 
outcomes in this population. The current study is also one of the few published that focuses specifically on an Indigenous population, providing critical evidence on an intervention with the potential to make a real difference for families living in conditions of risk.

Limitations include a lack of information about FFHV effectiveness for First Nations families living on-reserve, many of whom reside in rural/remote geographies. This will be addressed in our ongoing evaluation of a parallel home visiting programme, Strengthening Families, operating exclusively in First Nations communities in Manitoba. As well, despite the precautions we took to ensure the study groups had similar characteristics, we cannot assume that we have adjusted for all confounders, although the $\gamma$ sensitivity values for our findings suggest that confounding variables would generally need to have a very strong influence to negate the effects we observed.

\section{Public health implications}

The FFHV programme is an important public health delivery strategy for families experiencing multiple challenges, as it promotes childhood vaccination and helps connect parents to resources in their communities. While the success of FFHV in the general population has been previously established, this study provides additional evidence of programme effectiveness for First Nations families in Manitoba. Future qualitative research will help explain the mechanisms by which FFHV brings about improved public health outcomes in this population.

\section{Author affiliations \\ ${ }^{1}$ Manitoba Centre for Health Policy, Department of Community Health Sciences, Rady Faculty of Health Sciences, University of Manitoba, Winnipeg, Manitoba, Canada \\ ${ }^{2}$ First Nations Health and Social Secretariat of Manitoba, Winnipeg, Manitoba, Canada \\ ${ }^{3}$ Department of Family Medicine, Rady Faculty of Health Sciences, University of Manitoba, Winnipeg, Manitoba, Canada \\ ${ }^{4}$ Healthy Child Manitoba, Government of Manitoba, Winnipeg, Manitoba, Canada}

Contributors The study was conceived by MB, MC, JEE, NN, DC, RC, WP-B, EB and AK. The analyses were designed by NN and DC, and carried out by JS. JEE and MC drafted the manuscript. All coauthors, including all the aforementioned individuals as well as JBL and RS, participated in team meetings to discuss and interpret the study findings, conducted a critical review of the manuscript, and approved the final version.

Funding The study was supported through a Canadian Institutes of Health Research Operating Grant in Population Health Intervention Research to Promote Health and Health Equity, with sponsorship from the Institute of Population and Public Health and the CIHR Pathways to Health Equity for Aboriginal Peoples Initiative, in partnership with the Saskatchewan Health Research Foundation (grant number Gl1-145122).

Competing interests None declared.

Patient consent for publication Not required.

Ethics approval Approvals were granted by the Health Research Ethics Board at the University of Manitoba, the Health Information Privacy Committee of Manitoba, and the First Nations Health and Social Secretariat of Manitoba's Health Information Research Governance Committee.

Provenance and peer review Not commissioned; externally peer reviewed.

Data sharing statement The administrative and programme data used in this study are not publicly available, as they belong to the various Manitoba agencies and government departments that collect them through the healthcare system, social services and other programmes. A copy of these deidentified data is held securely at the Manitoba Centre for Health Policy, which facilitates the process of obtaining permissions to use them in research.

Open access This is an open access article distributed in accordance with the Creative Commons Attribution Non Commercial (CC BY-NC 4.0) license, which permits others to distribute, remix, adapt, build upon this work non-commercially, and license their derivative works on different terms, provided the original work is properly cited, appropriate credit is given, any changes made indicated, and the use is non-commercial. See: http://creativecommons.org/licenses/by-nc/4.0/.

\section{REFERENCES}

1. Stover GN, Bassett MT. Practice is the purpose of public health. Am J Public Health 2003;93:1799-801.

2. Brownson RC, Chriqui JF, Stamatakis KA. Understanding evidencebased public health policy. Am J Public Health 2009;99:1576-83.

3. Peacock S, Konrad S, Watson E, et al. Effectiveness of home visiting programs on child outcomes: a systematic review. BMC Public Health 2013;13:17.

4. Kitzman H, Olds DL, Henderson CR, et al. Effect of prenatal and infancy home visitation by nurses on pregnancy outcomes, childhood injuries, and repeated childbearing. A randomized controlled trial. JAMA 1997;278:644-52.

5. Olds DL, Sadler L, Kitzman H. Programs for parents of infants and toddlers: recent evidence from randomized trials. J Child Psychol Psychiatry 2007;48:355-91.

6. Green BL, Ayoub C, Bartlett JD, et al. The effect of early head start on child welfare system involvement: a first look at longitudinal child maltreatment outcomes. Child Youth Serv Rev 2014;42:127-35.

7. Isaac MR, Chartier M, Brownell M, et al. Can opportunities be enhanced for vaccinating children in home visiting programs? A population-based cohort study. BMC Public Health 2015;15:620.

8. Chartier MJ, Brownell MD, Isaac MR, et al. Is the families first home visiting program effective in reducing child maltreatment and improving child development? Child Maltreat 2017;22:121-31.

9. Chartier M, Nickel NC, Chateau D, et al. Families First Home Visiting programme reduces population-level child health and social inequities. J Epidemiol Community Health 2018;72:47-53.

10. Lemstra M, Neudorf C, Opondo J, et al. Disparity in childhood immunizations. Paediatr Child Health 2007;12:847-52.

11. Wilson LA, Pakes B, Murphy MSQ, et al. Connecting remote populations to public health: the case for a digital immunisation information system in Nunavut. Int J Circumpolar Health 2017;76:1358566.

12. Bombay A, Matheson $\mathrm{K}$, Anisman $\mathrm{H}$. Intergenerational trauma: convergence of multiple processes among First Nations peoples in Canada. J Aborig Heal 2009;5.

13. Truth and Reconciliation Commission of Canada. Honouring the truth, reconciling the future: summary of the final report of the truth and reconciliation commission of Canada: Truth and Reconciliation Commission of Canada, 2015.

14. Greenwood ML, de Leeuw SN. Social determinants of health and the future well-being of Aboriginal children in Canada. Paediatr Child Health 2012;17:381-4.

15. Statistics Canada. Focus on geography series, 2011 Census. 2015 https://www12.statcan.gc.ca/census-recensement/2011/as-sa/fogsspg/Index-eng.cfm (Accessed March 4, 2019).

16. The social and aboriginal statistics division of statistics Canada. Fact Sheet for Manitoba: Aboriginal Peoples, 2016.

17. Healthy Child Manitoba. Families first program evaluation: evaluating the effectiveness the families first home visiting program in improving the well-being of at-risk families with preschool children. Winnipeg, Manitoba: Government of Manitoba, 2010.

18. Korfmacher J. The Kempe Family Stress Inventory: a review. Child Abuse Negl 2000;24:129-40.

19. Growing Great Kids Inc. Prenatal to 36 months: an interactive parenting and child development program and staff development program, 2015.

20. Nickel NC, Chateau DG, Martens PJ, et al. Data resource profile: pathways to health and social equity for children. Int J Epidemiol 2014;43.

21. Roos LL, Menec V, Currie RJ. Policy analysis in an information-rich environment. Soc Sci Med 2004;58:2231-41.

22. Roos LL, Gupta S, Soodeen RA, et al. Data quality in an information-rich environment: Canada as an example. Can J Aging 2005;24(Suppl 1):153-70.

23. Rubin D. Multiple imputation for non-response in surveys. New York: John Wiley and Sons, 1987. 
24. Jones DE, Greenberg M, Crowley M. Early social-emotional functioning and public health: the relationship between kindergarten social competence and future wellness. Am J Public Health 2015;105:2283-90.

25. Rosenbaum P. Observational studies. New York: Springer-Verlag New York Inc, 2010.

26. SAS Institute. SAS, 2011.

27. Wacholder S. Binomial regression in GLIM: estimating risk ratios and risk differences. Am J Epidemiol 1986;123:174-84.

28. Herring S, Spangaro J, Lauw M, et al. The Intersection of Trauma, Racism, and Cultural Competence in Effective Work with Aboriginal People: Waiting for Trust. Australian Social Work 2013;66:104-17.

29. Bennett B, Redfern H, Zubrzycki J. Cultural responsiveness in action: co-constructing social work curriculum resources with aboriginal communities. Br J Soc Work 2018;48:808-25.

30. Lavoie JG. Policy silences: why Canada needs a National First Nations, Inuit and Métis health policy. Int J Circumpolar Health 2013;72:22690.

31. Richmond CAM, Cook C. Creating conditions for Canadian aboriginal health equity: the promise of healthy public policy. Public Health Rev 2016;37.

32. Kirmayer LJ, Gone JP, Moses J. Rethinking historical trauma. Transcult Psychiatry 2014;51:299-319.
33. Richmond CAM, Ross NA. The determinants of First Nation and Inuit health: a critical population health approach. Health Place 2009;15:403-11.

34. Larcombe L, Nickerson $\mathrm{P}$, Singer $\mathrm{M}$, et al. Housing conditions in 2 Canadian First Nations communities. Int J Circumpolar Health 2011;70:141-53.

35. Canada H. First nations mental wellness continuum framework. Ottawa, ON, 2015.

36. Cramer J, Chartier M, Brownell M, et al. Are home visiting programs for at-risk families effective in improving child outcomes? A PATHS equity for children project: Meeting of Western and North-Western Ministers Responsible for Child Welfare, 2014.

37. Durlak JA, DuPre EP. Implementation matters: a review of research on the influence of implementation on program outcomes and the factors affecting implementation. Am J Community Psychol 2008;41:327-50.

38. O'Brien RA, Moritz P, Luckey DW, et al. Mixed methods analysis of participant attrition in the nurse-family partnership. Prev Sci 2012;13:219-28.

39. Prinz RJ, Smith EP, Dumas JE, et al. Recruitment and retention of participants in prevention trials involving family-based interventions. Am J Prev Med 2001;20(1 Suppl):31-7.

40. Chateau D, Metge $\mathrm{C}$, Prior $\mathrm{H}$, et al. Learning from the census: the Socio-economic Factor Index (SEFI) and health outcomes in Manitoba. Can J Public Heal 2012:S23-7. 